\title{
Association between the polymorphism of the goat stearoyl-CoA desaturase 1 (SCD1) gene and milk fatty acid composition in Murciano-Granadina goats
}

\author{
A. Zidi, ${ }^{*}$ V. M. Fernández-Cabanás,† B. Urrutia,ł J. Carrizosa,ł O. Polvillo,† P. González-Redondo,† \\ J. Jordana, ${ }^{*}$ D. Gallardo, ${ }^{*}$ M. Amills, ${ }^{* 1}$ and J. M. Serradilla ${ }^{1}$ \\ *Departament de Ciència Animal i dels Aliments, Universitat Autònoma de Barcelona, 08193 Bellaterra, Spain \\ †Departamento de Ciencias Agroforestales, Escuela Universitaria de Ingeniería Técnica Agrícola-Universidad de Sevilla, Carretera Utrera, km. 1, \\ 41013 Sevilla, Spain \\ †Instituto Murciano de Investigación y Desarrollo Agrario y Alimentario (IMIDA), Estación Sericícola, La Alberca, Murcia, Spain \\ §Departamento de Producción Animal, Campus de Rabanales, Universidad de Córdoba, 14071 Córdoba, Spain
}

\section{ABSTRACT}

Genetic variability of the caprine stearoyl-CoA desaturase 1 ( SCD1) gene has been investigated by sequencing a 4.7-kb cDNA in 6 goats from the MurcianoGranadina and Malagueña breeds. Sequence alignment revealed the existence of one synonymous polymorphism at exon $5($ c.732C $>\mathrm{T})$ and one nucleotide substitution (c. ${ }^{*} 3504 \mathrm{G}>\mathrm{A}$ ) at exon 6 that encodes the $3^{\prime}$ untranslated region (UTR). Moreover, the existence of a previously reported $3^{\prime} \mathrm{UTR}$ polymorphism involving a 3-bp indel (c.*1902_1904delTGT) was confirmed. Single nucleotide polymorphism and haplotype-based association analyses revealed suggestive associations between genetic variability of the $S C D 1$ locus and lactose, stearic, polyunsaturated, and conjugated linoleic fatty acid contents. Associations with milk fatty acid composition might be explained by the global effects that SCD1 exerts on mammary gland lipid metabolism through the down-modulation of key transcription factors. Interestingly, the performance of an in silico analysis revealed that the c.*1902_1904delTGT polymorphism involves a considerable change in the secondary structure of the SCD1 mRNA. Gene reporter assays and quantitative PCR analysis would be needed to assess if this mutation has a causal effect on milk polyunsaturated and conjugated linoleic fatty acid levels by altering the amount of $S C D 1$ transcripts in mammary epithelial cells.

Key words: goat, stearoyl-CoA desaturase, milk fatty acid, lipid metabolism

\section{INTRODUCTION}

Milk fatty acid (FA) composition is an important trait for the goat dairy industry because of its influ-

\footnotetext{
Received July 29, 2009.

Accepted May 8, 2010.

${ }^{1}$ Corresponding authors: Marcel.Amills@uab.cat and pa1semaj@ uco.es
}

ence on cheese yield and the organoleptic properties of dairy products (Chilliard et al., 2003). Goat milk is particularly rich in saturated fatty acids (SFA; $55 \%$ of total milk triacylglycerols), whereas monounsaturated (MUFA, 29\%) and polyunsaturated (PUFA, 16\%) FA are less abundant (Fontecha et al., 2000). Because dietary SFA are associated with the occurrence of coronary and atherosclerotic diseases in humans, increasing the unsaturated FA milk content would be highly beneficial.

Milk FA composition is affected by nutritional and genetic factors. For instance, supplementing a low forage diet with sunflower oil involves a substantial increase in the milk content of C18:1 and C18:2 isomers and a reduction in medium-chain SFA (Ollier et al., 2009). Lactation stage and energy balance (Chilliard et al., 2003), udder health (Jensen, 2002), and seasonal variations in the lipid content of pastures (Meluchová et al., 2008) are other factors that influence milk FA composition. From a genetic perspective, Arnould and Soyeurt (2009) have reported moderate heritability values for dairy cattle milk SFA $\left(\mathrm{h}^{2}=0.36\right)$, MUFA $\left(\mathrm{h}^{2}=0.09-0.17\right)$, and PUFA $\left(\mathrm{h}^{2}=0.25\right)$, indicating that there is a considerable amount of additive variance for these traits. Additionally, multiple QTL for milk FA composition phenotypes have been reported in cattle (Schennink et al., 2009; Stoop et al., 2009) and sheep (García Fernández et al., 2010a,b). Candidate gene studies have also shown the existence of significant associations between specific genotypes and milk FA content (Moioli et al., 2007). Taken together, these results suggest that milk FA composition can be modified through selection.

Consistent and significant associations have been found between the polymorphism of the bovine stearoylCoA desaturase 1 ( $\boldsymbol{S C D 1}$ ) gene and milk FA composition traits (Taniguchi et al., 2004; Mele et al., 2007; Jiang et al., 2008; Schennink et al., 2008; Kgwatalala et al., 2009). The SCD1 enzyme catalyzes the introduction of a $\Delta^{9}$-cis double bond in saturated fatty acyl CoA, a 
fundamental step in the synthesis of MUFA (Miyazaki and Ntambi, 2003). This enzyme also plays an essential role in the synthesis of milk CLA in ruminants (Khanal and Dhiman, 2004). In goats, the sequence and chromosomal location of the $S C D 1$ gene have been reported and a single TGT indel polymorphism has been identified in the 3' untranslated region (UTR; Bernard et al., 2001; Yahyaoui et al., 2002). The main goal of the current work was to investigate if genetic variability at the goat $S C D 1$ gene is associated with milk FA content and other milk traits.

\section{MATERIALS AND METHODS}

\section{Animal Material and Phenotype Recording}

A total of 452 Murciano-Granadina goats were used to estimate the genotype frequencies of the $S C D 1$ gene. Murciano-Granadina is a black-coated dairy breed mainly distributed in southeast Spain (Gonzalo et al., 2002). Milk from Murciano-Granadina goats is mainly devoted to the manufacture of fresh, semi-aged, and aged cheese with appellation of origin (cheese of Murcia). Analyses were performed in 2 Murciano-Granadina groups of goats including 4 herds (Supplementary Figure 1; available online at http://www.journalofdairyscience.org/). All herds were under an official milk recording scheme and they were raised under a fully intensive management system. Kidding took place throughout the year with 2 peaks in fall (groups 1 and 2) and winter (group 1). Sampling procedures and traits recorded for group 1 $(\mathrm{n}=133)$ have been reported in Badaoui et al. (2007). With regard to group $2(\mathrm{n}=176)$, whole milk produced in the first of the 2 daily milkings was collected and measured approximately every 2 mo (65.5-d average sampling interval), starting around the third month after parturition (average $97.7 \mathrm{~d}$ ). Milk samples were stored in iceboxes and transported to the laboratory, where protein, fat, lactose, and DM contents and SCC were measured with a CombiFoss 600FC instrument (comprising a MilkoScan FT 6000 for the analysis of milk components and a Fossomatic FC for SCC; Foss Electric, Hillerød, Denmark). A small sample $\left(10 \mathrm{~cm}^{3}\right)$ of milk from each goat was freeze-dried, stored at $-20^{\circ} \mathrm{C}$ (average $3 \mathrm{mo}$ ), and subsequently used for the gas chromatography analyses of FA.

\section{Gas Chromatography Analysis}

Separation and quantification of fatty acid methyl esters were carried out using a gas chromatograph Agilent 6890N Network GS System (Agilent, Santa Clara, CA), equipped with a flame-ionization detector and fitted with an HP-88 capillary column (100 m,
$0.25 \mathrm{~mm}$ i.d., $0.2-\mu \mathrm{m}$ film thickness). Nonanoic acid methyl ester (C9:0 ME) at $4 \mathrm{mg} / \mathrm{mL}$ was used as an internal standard. Extraction and direct methylation were performed in a single-step procedure based on the method published by Sukhija and Palmquist (1998). Individual FA were identified by comparing their retention times with those of an authenticated standard FA mix Supelco 37 (Sigma Chemical Co. Ltd., Poole, UK). Identification of the conjugated linoleic acid (CLA) isomers cis-9,trans-11, cis-11,trans-13, trans-10,cis-12, and cis-10,cis-12 CLA was achieved by comparing retention times with those of another authenticated standard mix (Sigma Chemical Co. Ltd.). Fatty acid content was expressed as the percentage of total methyl esters identified and grouped as follows: SFA, MUFA, and PUFA. Desaturase indices were calculated from specific FA to estimate SCD1 activity. These indices were calculated as a ratio of product/substrate (Lock and Garnsworthy, 2003). The following indices were calculated: C14 index, C16 index, C18 index, and CLA index.

\section{Sequence Analysis and Genotyping of the Goat SCD1 Gene}

Total RNA was extracted from liver tissue of Murciano-Granadina $(\mathrm{n}=3)$ and Malagueña goats $(\mathrm{n}=$ 3) using the RiboPure Kit (Ambion Inc., Austin, TX), and complementary DNA was synthesized with the ThermoScript RT-PCR kit (Invitrogen S.A., Barcelona, Spain) according to Zidi et al. (2008). The coding sequence and part of 3'UTR (from 141 to 5012 bp, GenBank accession no. AF325499) of the goat SCD1 gene was amplified by using 6 primer pairs. Amplification protocols (PCR1 to PCR6) are reported in Supplementary Table 1 (available online at http://www. journalofdairyscience.org/). Amplified products were sequenced in both directions. Sequencing reactions were purified by using the Montage $\mathrm{SEQ}_{96}$ cleanup kit (Millipore Corporation, Billerica, MA). Sequencing reactions were analyzed in an ABI PRISM 3730 capillary electrophoresis device (Applied Biosystems, Sant Andreu de Llavaneres, Spain).

Genomic DNA was extracted from blood samples of all 452 goats (Supplementary Figure 1) following Caravaca et al. (2009). Polymorphic regions were amplified as described in Supplementary Table 1 (PCR7 to PCR9). The PCR products were purified by using the ExoSAP-IT kit (Amersham Biosciences Europe GmbH, Barcelona, Spain). Genotyping was performed either with the SNaPshot ddNTP Primer Extension kit (Applied Biosystems) or with the Sequenom MassARRAY iPLEX platform at the Spanish National Genotyping Centre (CeGen, Santiago de Compostela, Spain). The extension primers used in the primer-extension geno- 
typing protocol were $5^{\prime}$-GTG AAA CGT TTC AAA A-3' (polymorphism c.732C > T), 5'-GCC GAA TGC TCA TGT-3' (c.*1902_1904), and 5'-TTT TAT AAA GCA TCT TGG A-3' (c. ${ }^{*} 3504 \mathrm{G}>\mathrm{A}$ ). The existence of Hardy-Weinberg equilibrium for the 3 polymorphisms was tested with the Hardy-Weinberg equilibrium online tool (http://www.oege.org/software/hwe-mr-calc. shtml; Rodríguez et al., 2009).

\section{In Silico Analyses of mRNA Secondary Structure and 3'UTR Functional Motifs}

An in silico search of functional sequence motifs and microRNA target sites in the $3^{\prime} \mathrm{UTR}$ of the goat $S C D 1$ gene was performed by using programs RNA Analyzer (Bengert and Dandekar, 2003; http://wb2x01.biozentrum.uni-wuerzburg.de), UTRscan (Pesole and Liuni, 1999; http://www.ba.itb.cnr.it/BIG/UTRScan), and TargetScan 5.1. (http://www.targetscan.org). Moreover, the effects of the 3 polymorphisms on mRNA secondary structure were analyzed. Fragments encompassing 50- to 80-bp sequences flanking each polymorphism were evaluated with RNAfold (Gruber et al., 2008) and Mfold (Zuker, 2003) under default parameters.

\section{Statistical Analysis}

Associations between SCD1 genotypes and traits under study were analyzed with the SAS software (SAS 9.2, SAS Inst. Inc., Cary, NC) using a mixed model for repeated measurements (Littell et al., 1998). The number of goats with records for milk yield, somatic cell count logarithmic (logSCC) and milk protein, fat, lactose, and dry matter contents was 309 (133 goats from group 1 and 176 from group 2), whereas for milk FA composition, data from 176 goats (group 2) were employed (Supplementary Figure 1). Statistical analyses were performed taking into consideration single polymorphisms or haplotypes as well as fixed factors with significant effects on the traits under study. Haplotypes were inferred using the PHASE program v. 2.0 (Stephens et al., 2001). Haplotype substitution effects were exclusively calculated for the 2 most frequent haplotypes; that is, T/DelTGT/G and C/TGT/A. They were estimated considering the number of copies of haplotype T/DelTGT/G as a variable that can take values of 1 (goats homozygous for the T/DelTGT/G haplotype), 0 (heterozygous goats: T/DelTGT/G-C/ TGT/A), and -1 (C/TGT/A homozygous goats). The model used for analyzing dairy traits (milk yield, and protein, fat, lactose, and DM contents) included as fixed factors SCD1 genotype/haplotype, ordinal number of lactation $(1,2,3$, and $>3)$, number of kids born $(1,2$, and $\geq 3$ ), month of lactation (1 to 9 ), herd (4 levels), season of sampling (4 levels), the random animal effect, and the residual error term. Log SCC was used as a covariate in the statistical model. The statistical model used to analyze milk FA composition was similar to the one described previously, but there were 2 main differences: 1) the herd effect was not included in the model (because all goats from group 2 belonged to a single herd) and 2) season of sampling had 3 levels: fall, winter, and spring (the number of summer records was very low so they were added to the spring class). LogSCC was also used as a covariate in the statistical analysis of milk FA data (Jensen, 2002). Bonferroni threshold of significance was computed as the ratio between the original significance level (e.g., 0.05) and the number of hypothesis tests. The Bonferroni thresholds of significance for FA composition and milk yield traits were 0.0013 and 0.0083 , respectively. Results with $P_{-}$ values between the Bonferroni threshold and 0.01 have been considered as highly suggestive and those with $P$-values between 0.01 and 0.05 as suggestive.

\section{RESULTS AND DISCUSSION}

The variability of the goat $S C D 1$ gene was assessed by amplifying and sequencing $4.7 \mathrm{~kb}$ of cDNA. This sequence encompassed most of the coding region (95\%) and the $3^{\prime}$ UTR (96\%) of the caprine SCD1 gene. Alignment of 6 goat $S C D 1$ sequences revealed the existence of 3 polymorphisms: one synonymous c.732C $>\mathrm{T}$ polymorphism at exon 5, one TGT indel at the $3^{\prime} \mathrm{UTR}$ (c.*1902_1904delTGT, exon 6), that was previously reported by Bernard et al. (2001), and a c.*3504G > A substitution also located in the $3^{\prime} \mathrm{UTR}$. Genotype and haplotype frequencies are shown in Table 1. These data demonstrate the existence of linkage between c. ${ }^{*} 1902 \_1904 d e l T G T$ and c. ${ }^{*} 3504 \mathrm{G}>$ A polymorphisms. No significant departure from Hardy-Weinberg equilibrium was detected. PHASE analysis revealed the existence of 8 haplotypes, of which 2 are the majority ones with a global frequency of 0.91 (Table 1).

Phenotypic measurements obtained in the Murciano-Granadina resource population are presented in Supplementary Table 2 (all supplementary tables available online at http://www.journalofdairyscience. org/). The phenotypic means for dairy traits presented in the current work are within the range of what has been published so far in the Murciano-Granadina breed (Gonzalo et al., 2002; Fernández et al., 2005). Means of milk FA composition (Supplementary Table 2) were similar to those reported by Salama et al. (2005) in Murciano-Granadina dairy goats. However, several differences were observed. For instance, milk C6:0 content was $0.32 \%$ in the current experiment, whereas Salama et al. (2005) describe means of 1.12 to $1.45 \%$ for this 
Table 1. Genotype and haplotype frequencies of the stearoyl-CoA desaturase 1 (SCD1) gene in Murciano-Granadina goats $(\mathrm{n}=452)$

\begin{tabular}{|c|c|c|}
\hline Polymorphism & Genotype & Frequency \\
\hline \multirow[t]{3}{*}{ c. $732 \mathrm{C}>\mathrm{T}$} & $\mathrm{TT}$ & 0.49 \\
\hline & $\mathrm{CT}$ & 0.40 \\
\hline & $\mathrm{CC}$ & 0.11 \\
\hline \multirow[t]{3}{*}{ c. ${ }^{*} 1902 \_1904$ delTGT } & DelTGT/DelTGT & 0.55 \\
\hline & TGT/DelTGT & 0.38 \\
\hline & TGT/TGT & 0.07 \\
\hline \multirow[t]{3}{*}{ c. $* 3504 \mathrm{G}>\mathrm{A}$} & GG & 0.55 \\
\hline & GA & 0.38 \\
\hline & $\mathrm{AA}$ & 0.07 \\
\hline \multicolumn{3}{|l|}{ Haplotype } \\
\hline T/DelTGT/G & & 0.68 \\
\hline $\mathrm{C} / \mathrm{TGT} / \mathrm{A}$ & & 0.23 \\
\hline C/DelTGT/G & & 0.05 \\
\hline $\mathrm{T} / \mathrm{TGT} / \mathrm{G}$ & & 0.01 \\
\hline Remaining haplotypes $^{1}$ & & 0.03 \\
\hline
\end{tabular}

${ }^{1} \mathrm{~T} / \operatorname{DelTGT} / \mathrm{A}+\mathrm{T} / \mathrm{TGT} / \mathrm{A}+\mathrm{C} / \operatorname{DelTGT} / \mathrm{A}+\mathrm{C} / \mathrm{TGT} / \mathrm{G}$.

trait, which are 4-fold greater than ours. These differences among studies might be due to environmental factors (e.g., nutrition) or for technical reasons.

Performance of association analyses between $S C D 1$ single nucleotide polymorphisms versus dairy traits revealed suggestive associations with lactose percentage (c.732C $>$ T, $P=0.02$; c.*1902_1904delTGT, $P=$ 0.009 ; c. $\left.{ }^{*} 3504 \mathrm{G}>\mathrm{A}, P=0.02\right)$ as shown in Supplementary Table 3. Conversely, no association $(P>0.05)$ was observed between goat $S C D 1$ haplotypes and milk traits (Supplementary Table 4). The biological basis of these associations is unclear because $S C D 1$ is not functionally related to lactose metabolism in the mammary gland. Thus, it is possible that the associations detected in this work are the result of linkage disequilibrium with other causative mutations yet to be found. In this regard, it is worth mentioning that Schennink et al. (2008) did not find any significant association between an A293V substitution in the bovine SCD1 enzyme and protein and fat percentages and yields or milk production in Dutch Holstein-Friesian cattle.

The caprine $S C D 1$ genotype showed suggestive associations on milk FA composition (Table 2; Supplementary Tables 5 to 7 ). These associations were consistently found in both the single nucleotide polymorphism and haplotype-based analyses. In the latter, haplotype $\mathrm{T} /$ DelTGT/G was suggestively associated with a lower milk stearic FA content and with higher percentages of PUFA and total CLA compared with haplotype C/ TGT/A. Unexpectedly, none of the associations found involved MUFA content or desaturase indices (Supplementary Table 8). This negative result combined with the existence of associations with other FA is intriguing because the primary function of SCD1 is to synthesize
MUFA. In fact, association analyses between bovine $S C D 1$ genotype and milk FA traits have demonstrated the existence of effects on C10:1, C12:1 (Schennink et al., 2008; Kgwatalala et al., 2009), and C14:1 (Mele et al., 2007; Schennink et al., 2008). However, Bionaz and Loor (2008) failed to find associations between mammary gland SCD1 mRNA levels and desaturase indices, concluding that many other factors regulate milk FA output. These discrepancies among studies might be explained by the fact that $S C D 1 \mathrm{mRNA}$ expression varies throughout lactation, beginning to decay once the first 2 mo of milking have elapsed (Bionaz and Loor, 2008). This feature needs to be taken into account when evaluating our results because our sampling procedures began 3 mo after parturition.

Interestingly, associations between goat $S C D 1$ genetic variability and PUFA have been found (Table 2). Polyunsaturated fatty acids are essential FA not synthesized endogenously but acquired through the diet. Despite this feature, there is evidence that milk C18:2 and C18:3 contents are regulated not only by nutritional factors but also by genetic factors because heritabilities for milk PUFA content are low to moderate $\left(\mathrm{C} 18: 2, \mathrm{~h}^{2}=0.11\right.$ to $0.27 ; \mathrm{C} 18: 3, \mathrm{~h}^{2} \approx 0.09 ;$ Arnould and Soyeurt, 2009). To the best of our knowledge, genetic factors determining milk PUFA levels remain to be identified. Interestingly, Reh et al. (2004) engineered goats transgenic for the $S C D 1$ gene and observed that, among other changes, milk PUFA content was augmented. These findings suggest the existence of some type of interaction between expression levels of this desaturase and other genes, or biochemical pathways, influencing the uptake, esterification, or secretion of PUFA in the mammary gland. This interpretation agrees well with the multiple roles of SCD1 in the regulation of lipid and carbohydrate metabolism (Paton and Ntambi, 2009). In this way, microarray analysis of $S C D 1$ knockout mice fed a low-fat diet revealed that many genes involved in the hepatic biosynthesis, elongation, desaturation, oxidation, and transport of FA were differentially expressed compared with controls, an effect that is probably mediated through the down-modulation of key lipid metabolism transcription factors such as peroxisome proliferatoractivated receptor- $\alpha$, coactivator 1 of the peroxisome proliferator-activated receptor- $\gamma$, and sterol regulatory element-binding transcription factor 1 (Flowers et al., 2008). The highly suggestive association between $S C D 1$ genetic variability and milk trans-10,cis-12 CLA levels should also be understood in the light of the aforementioned interpretation, because this CLA isomer is exclusively produced by ruminal bacteria (Khanal and Dhiman, 2004). In contrast, suggestive associations with cis-9,trans-11 CLA (Table 2) can be understood more easily because this FA is mostly synthesized in 
the mammary gland by SCD using trans-vaccenic acid as a substrate (Griinari et al., 2000). In goats, the high correlation between CLA and trans-vaccenic acid in milk fat suggests the predominance of mammary gland endogenous versus ruminal synthesis (Chilliard et al., 2003).

The 2 SCD1 polymorphisms with suggestive associations are located in the $3^{\prime} \mathrm{UTR}$, a region that plays a fundamental role in the posttranscriptional regulation of gene expression and usually contains sequence motifs influencing translation efficiency and mRNA stability (e.g., AU-rich elements, selenocysteine insertion sequence elements, microRNA target sites; Grzybowska et al., 2001). Similarly, Jiang et al. (2008) have reported significant associations between 2 polymorphisms located in the $3^{\prime} \mathrm{UTR}$ of the bovine $S C D 1$ gene and muscle CLA content. These authors argued that these polymorphisms might affect a functional motif. In the current work, an in silico search of functional elements and microRNA target sites in the $3^{\prime} \mathrm{UTR}$ of the goat $S C D 1$ gene has been made with the RNA Analyzer, UTRscan, and TargetScan 5.1 software. This analysis did not yield evidence suggesting that the c.*1902_1904delTGT and c. $* 3504 \mathrm{G}>$ A polymorphisms might involve the creation or suppression of either a functional sequence motif or a microRNA target site. However, local analyses of mRNA secondary structure with RNAfold allowed us to infer that the c.732C > T and the c.*1902_1904delTGT polymorphisms alter this parameter, producing a conformational change that, in the case of c.*1902_1904delTGT, has dramatic consequences (Figures 1A to 1D). In this way, RNAfold analysis showed that the TGT deletion promotes the formation of a long stacked pair terminated in 2 small hairpin loops (Figure 1C and 1D). The in silico predictions obtained with Mfold were quite similar to the ones calculated with RNAfold (data not shown). Changes in $3^{\prime} \mathrm{UTR}$ mRNA secondary structure might have important consequences at many stages of posttranscriptional regulation (Chen et al., 2006). For instance, a polymorphism located in the $3^{\prime} \mathrm{UTR}$ of the protein phosphatase-1 regulatory subunit 3 (PPP1R3) gene, which involves a 5 -bp deletion plus 3 nucleotide substitutions, causes a severe reduction in the amount of PPP1R3 mRNA because of an increased degradation rate (Xia et al., 1999). This alteration has been associated with an increased susceptibility to type 2 diabetes in Pima Indians (Xia et al., 1998). Moreover, a 1-bp deletion in the $3^{\prime} \mathrm{UTR}$ of the natriuretic peptide receptor $\mathrm{A}(N P R 1)$ gene has been shown to produce a 3 -fold decrease in the amount of NPR1 transcripts possibly due to the loss of a binding site for a mRNAstabilizing trans-acting factor (Knowles et al., 2003). In summary, it would be worth investigating if the

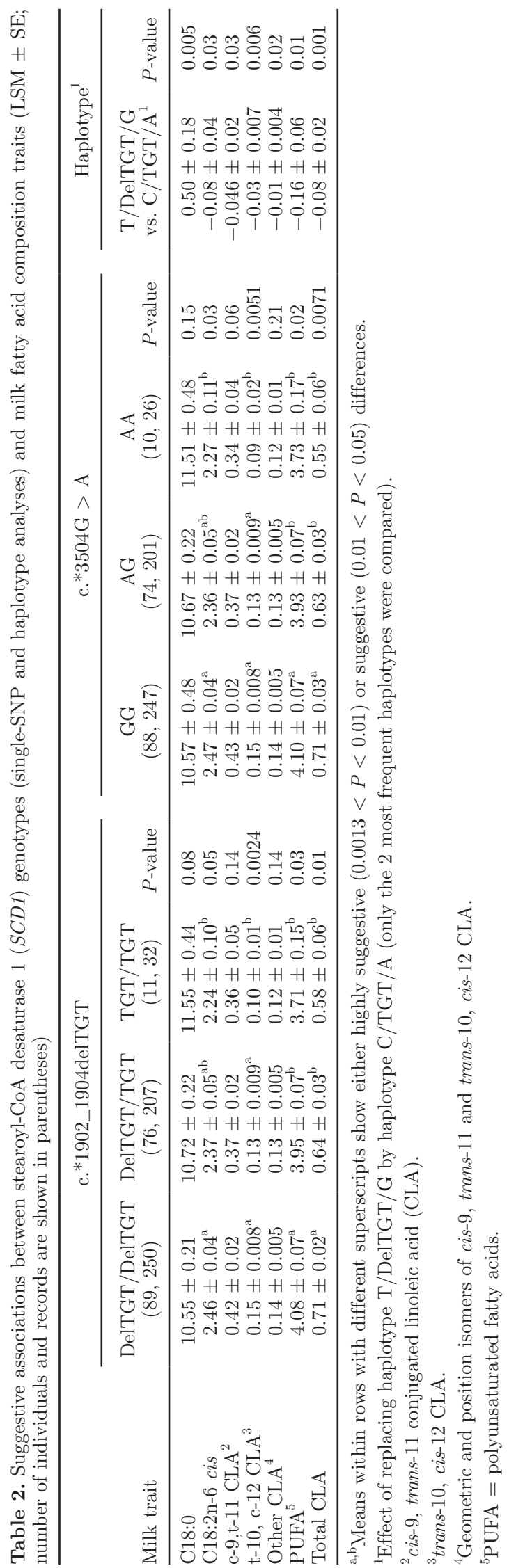




\section{POLYMORPHISM c.732C $>$ T}

(A) Minimum free energy: $-48.2 \mathrm{kcal} / \mathrm{mol}$

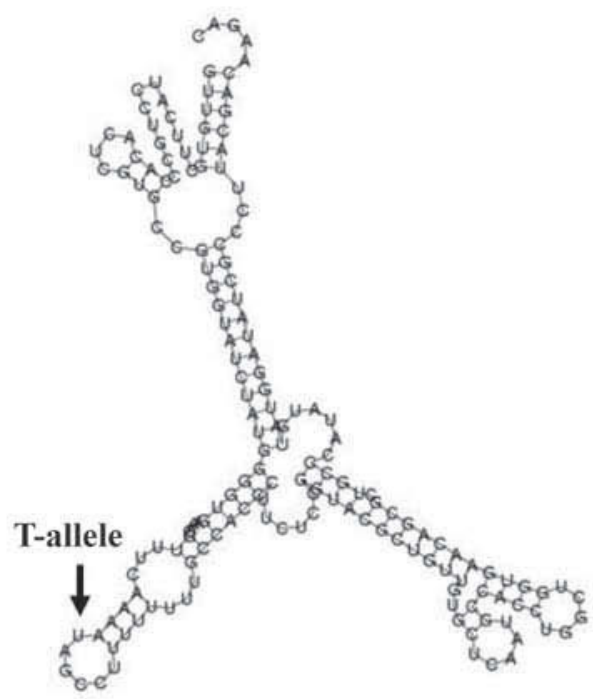

(B) Minimum free energy: $-49 \mathrm{kcal} / \mathrm{mol}$

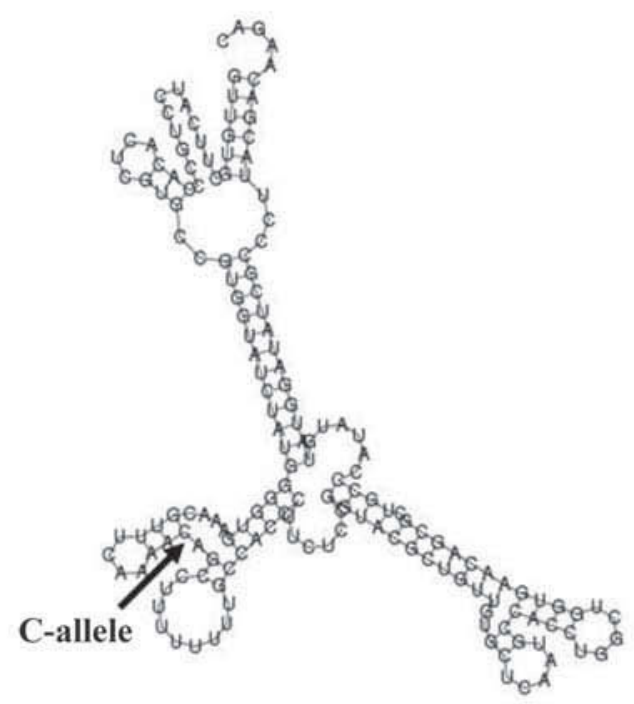

POLYMORPHISM c.*1902_1904delTGT

(C) Minimum free energy: $-51.9 \mathrm{kcal} / \mathrm{mol}$

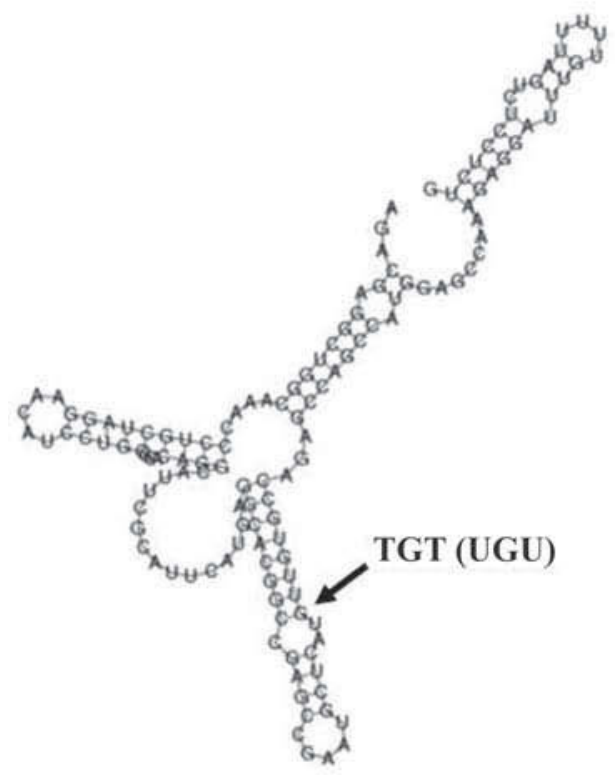

(D) Minimum free energy: $\mathbf{- 5 0 . 8} \mathrm{kcal} / \mathrm{mol}$

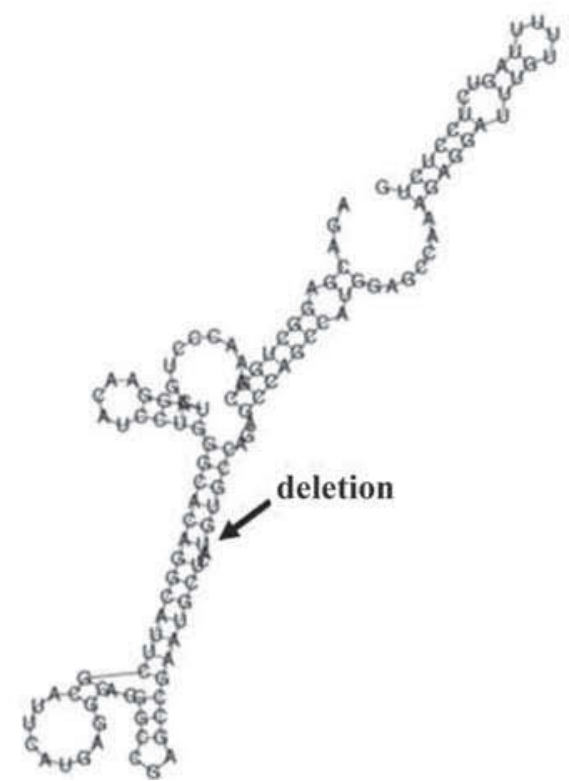

Figure 1. RNAfold (Gruber et al., 2008) prediction of the minimum free energy secondary structure of goat stearoyl-CoA desaturase 1 (SCD1) mRNA regions surrounding polymorphisms c.732C $>\mathrm{T}(\mathrm{A}=\mathrm{T}$-allele, $\mathrm{B}=\mathrm{C}$-allele $)$ and c. ${ }^{*} 1902 \_1904 d \mathrm{dTGT}(\mathrm{C}=\mathrm{TGT}$-allele, $\mathrm{D}=$ 3-bp deletion allele). 
c.*1902_1904delTGT polymorphism influences the amount of goat SCD1 mRNA through a change in the secondary structure of the $3^{\prime} \mathrm{UTR}$. An experimental approach relying on the utilization of gene reporter assays and quantitative PCR would be needed to analyze this issue. From a human health perspective, the $\mathrm{T} /$ DelTGT/G haplotype would be advantageous because it is associated with an increased amount of milk total CLA $(P=0.001)$, which has been associated with reduced susceptibility to cancer and atherosclerosis in diverse clinical studies (Bhattacharya et al., 2006).

\section{ACKNOWLEDGMENTS}

This research was funded by projects AGL200766161-C02-01 and AGL2007- 66161-C02-02. A. Zidi received fellowships of the Spanish Agency of International Cooperation and Development (Madrid, Spain) and the Center of Agrigenomic Research (CRAG, Campus of the Universitat Autònoma de Barcelona, Barcelona, Spain).

\section{REFERENCES}

Arnould, V. M., and H. Soyeurt. 2009. Genetic variability of milk fatty acids. J. Appl. Genet. 50:29-39

Badaoui, B., J. M. Serradilla, A. Tomàs, B. Urrutia, J. L. Ares, J. Carrizosa, A. Sànchez, J. Jordana, and M. Amills. 2007. Goat acetyl-coenzyme A carboxylase $\alpha$ : Molecular characterization, polymorphism, and association with milk traits. J. Dairy Sci. 90:1039-1043.

Bengert, P., and T. Dandekar. 2003. A software tool-box for analysis of regulatory RNA elements. Nucleic Acids Res. 31:3441-3445.

Bernard, L., C. Leroux, H. Hayes, M. Gautier, Y. Chilliard, and P. Martin. 2001. Characterization of the caprine stearoyl-CoA desaturase gene and its mRNA showing an unusually long 3'-UTR sequence arising from a single exon. Gene 281:53-61.

Bhattacharya, A., J. Banu, M. Rahman, J. Causey, and G. Fernandes, 2006. Biological effects of conjugated linoleic acids in health and disease. J. Nutr. Biochem. 17:789-810.

Bionaz, M., and J. J. Loor. 2008. Gene networks driving bovine milk fat synthesis during the lactation cycle. BMC Genomics 9:366.

Caravaca, F., J. Carrizosa, B. Urrutia, F. Baena, J. Jordana, M. Amills, B. Badaoui, A. Sànchez, A. Angiolillo, and J. M. Serradilla. 2009. Effect of $\alpha_{\mathrm{S}_{1}}$-casein $(C S N 1 S 1)$ and $\kappa$-casein $(C S N 3)$ genotypes on milk composition in Murciano-Granadina goats. J. Dairy Sci. 92:2960-2964.

Chen, J. M., C. Férec, and D. N. Cooper. 2006. A systematic analysis of disease-associated variants in the 3'regulatory regions of human protein-coding genes I: General principles and overview. Hum. Genet. 120:1-21.

Chilliard, Y., A. Ferlay, J. Rouel, and G. Lamberet. 2003. A review of nutritional and physiological factors affecting goat milk lipid synthesis and lipolysis. J. Dairy Sci. 86:1751-1770.

Fernández, C., M. L. Mocé, M. A. Latorre, and E. Gómez. 2005. Producción lechera de cabras Murciano-Granadinas de la región de Murcia. Ganadería (Madr.) 35:38-43.

Flowers, M. T., M. P. Keller, Y. J. Choi, H. Lan, C. Kendziorski, J M. Ntambi, and A. D. Attie. 2008. Liver gene expression analysis reveals endoplasmic reticulum stress and metabolic dysfunction in SCD1-deficient mice fed a very low-fat diet. Physiol. Genomics $33: 361-372$.
Fontecha, J., J. Ríos, L. Lozada, M. J. Fraga, and M. Juárez. 2000 Composition of goat's milk fat triglycerides analysed by silver ion adsorption-TLC and GC-MS. Int. Dairy J. 10:119-128.

García-Fernández, M., B. Gutiérrez-Gil, E. García-Gámez, J. P. Sánchez, and J. J. Arranz. 2010a. Detection of quantitative trait loci affecting the milk fatty acid profile on sheep chromosome 22: Role of the stearoyl-CoA desaturase gene in Spanish Churra sheep. J. Dairy Sci. 93:348-357.

García-Fernández, M., B. Gutiérrez-Gil, E. García-Gámez, J. P. Sánchez, and J. J. Arranz. 2010b. The identification of QTL that affect the fatty acid composition of milk on sheep chromosome 11. Anim. Genet. 41:324-328.

Gonzalo, C., C. Barba, and J. D. Gómez-Moya. 2002. Autochthonous caprine breeds. Ovis 83:25-28.

Griinari, J. M., B. A. Corl, S. H. Lacy, P. Y. Chouinard, K. V. Nurmela, and D. E. Bauman. 2000. Conjugated linoleic acid is synthesized endogenously in lactating dairy cows by $\Delta^{9}$-desaturase. J. Nutr. 130:2285-2291.

Gruber, A. R., R. Lorenz, S. H. Bernhart, R. Neuböck, and I. L. Hofacker. 2008. The Vienna RNA Websuite. Nucleic Acids Res. 36:W70-W74

Grzybowska, E. A., A. Wilczynska, and J. A. Siedlecki. 2001. Regulatory functions of 3 'UTRs. Biochem. Biophys. Res. Commun. 288:291295.

Jensen, R. G. 2002. The composition of bovine milk lipids: January 1995 to December 2000. J. Dairy Sci. 85:295-350.

Jiang, Z., J. J. Michal, D. J. Tobey, T. F. Daniels, D. C. Rule, and M. D. MacNeil. 2008. Significant associations of stearoyl-CoA desaturase (SCD1) gene with fat deposition and composition in skeletal muscle. Int. J. Biol. Sci. 4:345-351.

Kgwatalala, P. M., E. M. Ibeagha-Awemu, A. F. Mustafa, and X. Zhao 2009. Influence of stearoyl-coenzyme A desaturase 1 genotype and stage of lactation on fatty acid composition of Canadian Jersey cows. J. Dairy Sci. 92:1220-1228.

Khanal, R. C., and T. R. Dhiman. 2004. Biosynthesis of conjugated linoleic acid (CLA): A review. Pakistan J. Nutr. 3:72-81.

Knowles, J. W., L. M. Erickson, V. K. Guy, C. S. Sigel, J. C. Wilder, and N. Maeda. 2003. Common variations in noncoding regions of the human natriuretic peptide receptor $\mathrm{A}$ gene have quantitative effects. Hum. Genet. 112:62-70.

Littell, R. C., P. R. Henry, and C. B. Ammerman. 1998. Statistical analysis of repeated measures data using SAS procedures. J. Anim. Sci. 76:1216-1231.

Lock, A. L., and P. C. Garnsworthy. 2003. Seasonal variation in milk conjugated linoleic acid and $\Delta^{9}$-desaturase activity in dairy cows. Livest. Prod. Sci. 79:47-59.

Mele, M., G. Conte, B. Castiglioni, S. Chessa, N. P. P. Macciotta, A. Serra, A. Buccioni, G. Pagnacco, and P. Secchiari. 2007. Stearoylcoenzyme A desaturase gene polymorphism and milk fatty acid composition in Italian Holsteins. J. Dairy Sci. 90:4458-4465.

Mel'uchová, B., J. Blaško, R. Kubinec, R. Górová, J. Dubravská, M. Margetín, and L. Soják. 2008. Seasonal variations in fatty acid composition of pasture forage plants and CLA content in ewe milk fat. Small Rumin. Res. 78:56-65.

Miyazaki, M., and J. M. Ntambi. 2003. Role of stearoyl-coenzyme A desaturase in lipid metabolism. Prostaglandins Leukot. Essent. Fatty Acids 68:113-121.

Moate, P. J., W. Chalupa, R. C. Boston, and I. J. Lean. 2007. Milk fatty acids. I. Variation in the concentration of individual fatty acids in bovine milk. J. Dairy Sci. 90:4730-4739.

Moioli, B., G. Contarini, A. Avalli, G. Catillo, L. Orrù, G. De Matteis, G. Masoero, and F. Napolitano. 2007. Effect of stearoyl-coenzyme A desaturase polymorphism on fatty acid composition of milk. J. Dairy Sci. 90:3553-3558.

Ollier, S., C. Leroux, A. de la Foye, L. Bernard, J. Rouel, and Y Chilliard. 2009. Whole intact rapeseeds or sunflower oil in high-forage or high-concentrate diets affects milk yield, milk composition, and mammary gene expression profile in goats. J. Dairy Sci. 92:5544-5560. 
Paton, C. M., and J. M. Ntambi. 2009. Biochemical and physiological function of stearoyl-CoA desaturase. Am. J. Physiol. Endocrinol. Metab. 297:E28-E37.

Pesole, G., and S. Liuni. 1999. Internet resources for the functional analysis of $5^{\prime}$ and $3^{\prime}$ untranslated regions of eukaryotic mRNAs. Trends Genet. 15:378.

Reh, W. A., E. A. Maga, N. M. B. Collette, A. Moyer, J. S. ConradBrink, S. J. Taylor, E. J. DePeters, S. Oppenheim, J. D. Rowe, R. H. BonDurant, G. B. Anderson, and J. D. Murray. 2004. Hot Topic: Using a stearoyl-CoA desaturase transgene to alter milk fatty acid composition. J. Dairy Sci. 87:3510-3514.

Rodríguez, S., T. R. Gaunt, and I. N. Day. 2009. Hardy-Weinberg equilibrium testing of biological ascertainment for Mendelian randomization studies. Am. J. Epidemiol. 169:505-514.

Salama, A. A. K., G. Caja, X. Such, R. Casals, and E. Albanell. 2005. Effect of pregnancy and extended lactation on milk production in dairy goats milked once daily. J. Dairy Sci. 88:3894-3904.

Schennink, A., J. M. L. Heck, H. Bovenhuis, M. H. W. Visker, H. J. F. Van Valenberg, and J. A. M. van Arendonk. 2008. Milk fatty acid unsaturation: genetic parameters and effects of stearoyl-CoA desaturase (SCD1) and acyl CoA: diacylglycerol acyltransferase 1 (DGAT1). J. Dairy Sci. 91:2135-2143.

Schennink, A., W. M. Stoop, M. H. Visker, J. J. van der Poel, H. Bovenhuis, and J. A. M. van Arendonk. 2009. Short communication: Genome-wide scan for bovine milk-fat composition. II. Quantitative trait loci for long-chain fatty acids. J. Dairy Sci. 92:4676-4682.

Stephens, M., N. J. Smith, and P. Donnelly. 2001. A new statistical method for haplotype reconstruction from population data. Am. J. Hum. Genet. 68:978-989.
Stoop, W. M., A. Schennink, M. H. Visker, E. Mullaart, J. A. M. van Arendonk, and H. Bovenhuis. 2009. Genome-wide scan for bovine milk-fat composition. I. Quantitative trait loci for shortand medium-chain fatty acids. J. Dairy Sci. 92:4664-4675.

Sukhija, P. H., and D. L. Palmquist. 1998. Rapid method for determination of total fatty acid content and composition of feedstuffs and feces. J. Agric. Food Chem. 36:1202-1206.

Taniguchi, M., T. Utsugi, K. Oyama, H. Mannen, M. Kobayashi, Y. Tanabe, A. Ogino, and S. Tsuji. 2004. Genotype of stearoyl-CoA desaturase is associated with fatty acid composition in Japanese Black cattle. Mamm. Genome 15:142-148.

Xia, J., C. Bogardus, and M. Prochazka. 1999. A type 2 diabetesassociated polymorphic ARE motif affecting expression of PPP1R3 is involved in RNA-protein interactions. Mol. Genet. Metab. 68:48-55.

Xia, J., S. W. Scherer, P. T. Cohen, M. Majer, T. Xi, R. A. Norman, W. C. Knowler, C. Bogardus, and M. Prochazka. 1998. A common variant in PPP1R3 associated with insulin resistance and type 2 diabetes. Diabetes 47:1519-1524.

Yahyaoui, M. H., A. Sánchez, and J. M. Folch. 2002. Rapid communication: Partial nucleotide sequence of the goat stearoyl coenzyme A desaturase cDNA and gene structure. J. Anim. Sci. 80:866-867.

Zidi, A., A. Sànchez, G. Obexer-Ruff, and M. Amills. 2008. Sequence analysis of goat major histocompatibility complex class I genes. J. Dairy Sci. 91:814-817.

Zuker, M. 2003. Mfold web server for nucleic acid folding and hybridization prediction. Nucleic Acids Res. 31:3406-3415. 